\title{
From the "Collaborative" Perspective of Agricultural Colleges Innovation and Entrepreneurship Education
}

\author{
Chao Wang ${ }^{1, a}$ and Junzheng Wang ${ }^{1, b *}$ \\ ${ }^{1}$ Xincheng Street 2888, Changchun, Jilin Province 130118, PR China \\ a29251275@qq.com, b59545966 @ qq.com \\ *The corresponding author
}

Keywords: Collaborative; Agricultural institutions; Innovation and entrepreneurship education; University

\begin{abstract}
Collaborative Fusion and determination of innovation are the keys of development to innovation and entrepreneurship education. In the national economy and social development thirteenth five year plan of the new situation, the innovation and entrepreneurship education in Colleges and universities, especially in agricultural colleges and universities, should combine their professional characteristics, the establishment of cross training mechanism, for the construction of Frontier Science, for cultural heritage, industry oriented industry, collaborative innovation and entrepreneurship education system for regional development, achieve efficient development of innovation and entrepreneurship education of agricultural colleges and universities.
\end{abstract}

\section{Introduction}

Agricultural Colleges is the national training base Rural Development. Establishing a scientific system of entrepreneurship education can help students in the course of business less detours, reforming the education system is also pioneering agricultural colleges and universities, to improve their overall competitiveness breakthrough. In view of the current situation of innovation and entrepreneurship education in agricultural colleges and universities, it is necessary to develop collaborative innovation in accordance with the characteristics of the specialty. The "collaborative" of ideas into institutions of higher agricultural entrepreneurship education system, not only conforms to the development community in the national economy and social development thirteenth five year plan of the new situation, but also to build for scientific frontier and cultural heritage, industry-oriented industries, for collaborative innovation and entrepreneurship in regional development education system provides an effective way.

\section{Universities Collaborative Innovation Proposed}

In 2011, the centennial celebration of Tsinghua University, Hu Jintao in his speech for the first time formally proposed "collaborative innovation". He stressed: To actively promote collaborative innovation, through institutional innovation and policy program guide and encourage colleges and universities with scientific research institutions, enterprises depth cooperation, the establishment of collaborative innovation alliance to promote the sharing of resources, carried out jointly by major scientific research projects, made in key areas breakthrough results, and strive for building an innovative country to make a positive contribution [1]. Universities "collaborative innovation", innovation and entrepreneurship for college education provides a scientific road of sustainable development and building in the integration of "collaborative" Thought of Agricultural Entrepreneurship Education System institutions, to improve the level of agricultural entrepreneurship education institutions are of great significance. The "collaborative innovation, innovation and entrepreneurship education in Colleges and universities provide a scientific road of sustainable development, agricultural colleges and universities entrepreneurship education system construction into thought" cooperation " is of great significance for raising the level of entrepreneurship education in agricultural colleges and universities. 


\section{Connotation of Collaborative Innovation in Colleges and Universities}

The collaborative innovation is referring to in the process of innovation and entrepreneurship education in Colleges and universities, in Colleges and universities, research institutes, industry enterprise scientific research institutions of the three main platform, around common goals, to achieve resource sharing, collaborative innovation and construction of coordination, promoting the development of innovation and entrepreneurship education for University research collaborative innovation education system [2]. The collaborative innovation and entrepreneurship education provide the theoretical basis of the framework, making collaborative innovation is not only the overall goal and the play according to individual ability is emphasized the subject consciousness of integration, and coordinate the interaction between individuals, by constructing a unified platform for innovation, on the existing mode of education for rectification, realizing the organic cooperation of innovation and entrepreneurship education.

\section{Significance of Collaborative Innovation in Agricultural Universities}

To promote the integration of production with teaching, school-enterprise cooperation, optimizing the layout of professional discipline and talent training mechanism are stated by "Proposal of the CPC Central Committee thirteenth Five-Year Plan for National Economic and Social Development" .General Secretary Xi Jinping in the eighth session of the Fifth Plenary Session of the party's report pointed out: to stimulate innovation and entrepreneurial dynamism, and promote public entrepreneurship, innovation and peoples, release new demand, create new supply, promote new technologies, new industries, new industry flourish. Absolutely, innovation is still the national economy and social development thirteenth five year plan that focused, which is a necessary condition for the socialist construction. In the system of innovation and entrepreneurship education for college students into the collaborative innovation, is to make the power of socialist construction inspired contemporary college students to entrepreneurship, to rely on his hands and self realization.

Its Own Development Needs of Agricultural Colleges. As an important part of the national modern agricultural education, agricultural colleges and universities are fertile ground to cultivate and foster a large number of innovative awareness and ability of senior personnel of agriculture, the main camp of agricultural technology research and exploration of higher agricultural technology, is the source of knowledge innovation, knowledge dissemination bond [3]. The local ordinary agricultural colleges, is to serve the local economic development, agriculture, building a new socialist countryside indispensable main force. Compared with the common agricultural colleges agricultural colleges and universities, there is a gap in all aspects, for example in terms of school funding, laboratory level, teachers and so on, rely on their own level of scientific research and effort is difficult to have great progress. Therefore, the local agricultural institutions in order to develop themselves and enhance their overall competitiveness, we must work closely with universities and research institutions, to build a platform for innovation and entrepreneurship education and research play a provincial education department of education to develop agriculture focus on efforts to make common agricultural institutions in its own development and cooperation lateral longitudinal development strive to achieve a breakthrough, in order to meet the professional characteristics out of a road of development.

The Needs of Agricultural Modernization. As the "new four modernizations" weak link in the development of agricultural modernization is the key development projects under the national economy and social development thirteenth five year plan. The realization of farmers' income, the sustainable development of rural public utilities and agricultural development are inseparable from the green of higher agricultural education. Faced with scarce agricultural resources, over exploitation and pollution increase and other issues, in order to improve the competitiveness of national agriculture, agricultural industry must innovate, train a group to understand science, agriculture and skilled professional personnel, but also to encourage high-tech talent in agriculture business, in order to establish a scientific platform fundamentally agricultural development. The 
"collaborative" of agricultural colleges to infiltrate the idea of innovation and entrepreneurship education, guiding students to cooperative innovation, can develop a modern agriculture for senior personnel and collaborative innovation of compound talents under the guidance of "co-thinking", they will will become "independent self" to "work together" in collaboration inspired by the idea, to take the initiative to join the cause to agricultural entrepreneurs, promote development of agricultural modernization with the knowledge, promoting socialist rural economic development, ten thirty-five building blocks.

\section{Agricultural Cooperative College of Innovative Entrepreneurship Education}

In agricultural colleges and universities to carry out collaborative innovation and entrepreneurship education today, its own problems are obvious. Innovation form, the lack of the system, the thought is weak and so on the status of agricultural colleges and universities have seriously hindered the development of collaborative innovation and entrepreneurship education.

College Formal Collaborative Innovation. Proposed foreign "collaborative" concept, the earliest in 1971. In 2001, the British scholar proposed collaborative innovation on university education. Universities abroad for collaborative innovation awareness is relatively advanced. In contrast, Chinese universities collaborative innovation started late, from General Secretary $\mathrm{Hu}$ Jintao first proposed collaborative innovation so far, but five years or so, so the collaborative innovation of university education is still in the road to discovery For most ordinary agricultural colleges, innovation and entrepreneurship in their educational process, collaborative innovation is just the form of "cooperation." Some agricultural colleges in the schools just by putting up posters, to carry out general education lectures, collaborative innovation had general publicity, the students know the concept of co-existence, and how cooperative and how innovation is still just a concept book lecture only; Other schools only on existing and innovative education to achieve a formal union between simplicity universities, the actual operation is still all walks of things, and not really digging collaborative innovation connotation from behind the joint, just stay in form on the "collaborative."

Universities Lack of Institutional Collaboration. Efficient and collaborative innovation must be top-down unified collaboration. This requires that colleges and universities need for a sound management mechanism and organizational operation mechanism. For the moment, it is difficult to achieve this effect. First, participation in collaborative innovation of agricultural colleges uneven, students of tertiary professional level, all types of professional level of teachers have high and low, is difficult to have a leader appears as an organizer, not the leader of the team is not competitive ;Secondly, because of the different levels of schools to recruit students of different levels of education and teaching goals are different, it is difficult to establish an effective mechanism to balance the interests of all parties to manage, so that once the system is not binding, cooperative entrepreneurship education is difficult to proceed, presented the status will always disunity [4].Finally, the Innovation Collaborative agricultural institutions not forming system for the establishment of the system of innovation, reform and innovation model, enterprise education and entrepreneurship education are summarized later issues such as research is still relatively lacking, we do not have a perfect system support, collaborative innovation process is difficult to control at the macro level.

Students Cooperative Thought Weak. In the entrepreneurship education system of agricultural universities, the cooperation between teachers and students, the cooperation between the entrepreneurial team, and the cooperation between colleges and universities is very necessary. Data show that, on "whether good initiative to explore cooperation with team members," this issue, $36.2 \%$ of the students are not good at or not good at completely, and nearly a third of the students on this issue expressed unsure [5], which is to enhance students' enthusiasm to participate in the entrepreneurial team put forward higher requirements. The start-up team for the teachers and students, most teachers just assumed the early guidance for the entrepreneurial process intervene less, which is a reflection of weak entrepreneurship education in agricultural universities of the 
status. Common agricultural institutions as the emphasis on agriculture and forestry institutions of higher learning, but should be a comprehensive university class or the same as the famous of agricultural colleges and universities as "985", "211" cooperation platform to establish entrepreneurship education in universities, learn the essence from different entrepreneurship education and then develop their own innovation and entrepreneurship education. In fact, this type of collaborative innovation platform for entrepreneurship education and even fewer.

\section{The Effective Approach of "Collaborative Innovation" into the Entrepreneurship Education in Agricultural Colleges}

And Scientific Collaboration, to Build a Platform for Innovation and Entrepreneurship. The establishment of collaborative innovation for cutting-edge science, between colleges and universities, between universities and research institutes powerful combination, to build a platform for innovation and entrepreneurship. And scientific collaboration, lessons a viable collaborative innovation at the establishment of a large number of scientific projects which contains South Korea, the United States and other countries [6], the establishment of different disciplines, including schools, businesses, research institutions, including cross entrepreneurship education system, which not only makes school cooperation between enterprises more closely, but also attract more schools involved, expansion of university education system build business collaboration team. First with a high level of collaborative College attract and gather a number of domestic and foreign talents and team building structure is reasonable, appropriate scale cooperative team, and invited in academia have a certain influence and prestige as a leader in academics, colleges and universities rely on a high level national key laboratories, research centers and other research will enhance the level of ordinary agricultural universities a big step; Second collaboration with similar institutions, to enhance innovation and entrepreneurship education for agricultural college in the entrepreneurship competition setting, jointly organized with major colleges and universities, including different settings, including school students entrepreneurial team, not only played all the advantages of students, offering the opportunity to learn from different schools of the student body. Finally, collaboration with research institutions, research personnel of university students entrepreneurial counseling, colleges and universities to establish business park, to strengthen the exchange of scientific information in the forefront, and students recommend a good business opportunity, the creation of a joint research project to improve the strength of scientific research university.

And Collaborative Culture, Heritage of Innovation and Entrepreneurial Ideas. The establishment of collaborative innovation for the cultural heritage, mainly to the theme of philosophy and Social Sciences through collaborative innovation, the development of innovative cultural institution soft power, such collaborative innovation to enhance entrepreneurship education become influential university main camp. Collaborative innovation, requires first breaking down traditional culture and education of people stick to the philosophy of education, change "isolated operation" to "collaboration", the people inherent isolated Unicom to change the direction of scientific research, and only from the fundamental idea of liberation, innovation culture can be developed and heritage. Under the national economy and social development thirteenth five year plan, to improve the cultural soft power is an important aspect of national development of science, and innovation is the key to this development on the layout.

Collaboration with Industry, Keeping up with the Pace of Business Development. Establishment of collaborative innovation for the industry, industry, universities should keep abreast of industry, industry development trends, to develop in line with the national and industrial development of the industry innovation in educational planning, the formation of a reasonable collaborative innovation body, the choice of partner, we should and have good long-term basis to give full recognition of the industry, industrial sector companies, so as to make the pace of innovation and entrepreneurship education closely follow the development of the industry. Teachers of Colleges to break carry out scientific research in the narrow areas and enclosed space situation, to learn the laws of scientific research and the market and the laws of social development combined joint entrepreneurship education with the government and emerging industries, will guide the 
students' innovation and entrepreneurship education by the team of "small entrepreneurs" into social services, to promote industrial development of the industry "big business" [7].To learn more enterprise management, conduct effective mechanism reform, so set reasonable personnel structure, clear division of labor, their duties, and thus the initial formation of fusion research with development, organized a new development situation[8]. At the same time, in today's the national economy and social development thirteenth five year plan under the Agricultural Universities of innovation and entrepreneurship education should focus on service "three rural", always concerned about the new situation "three rural" problems, the new trend of development, and actively play their own advantage, guide students to leave the campus at the grassroots level in rural areas to carry out agricultural practices, mining venture projects in rural areas, really into to promote the "three rural" development of the road up [9].

And Regional Development Cooperation, to Achieve the Goal of Entrepreneurship Education. Establishing collaborative innovation-oriented regional development is the he ultimate goal of serving the local economy that needs entrepreneurship education and training to achieve entrepreneurial talent [10].Jilin Agricultural University, located in Changchun City, Jilin Province, is located in the center of the northeast old industrial base, and therefore innovation and entrepreneurship education should be to revitalize the old northeast industrial base as the ultimate goal. Innovation and entrepreneurship education in agricultural universities should be to serve the regional economy as the focus, focus on planning in line with local industry and social development, through the three northeastern provinces and pillar industries and key enterprises depth cooperation, to promote regional economic development a good situation. Regional economic development lies in improving the capability of independent innovation, and innovation and entrepreneurship education platform for enterprises to provide university just start simulation platform. Major universities and enterprises needs joint body disciplines meet regional development, common structures corresponding key research base, relying on the National Science and Technology Innovation Fund project, the construction of a first-class platform for entrepreneurship education, colleges and universities breakthrough research problems to solve key technical enterprises, enterprises seeking continuous development momentum. Finally, collaborative innovation and entrepreneurship education better get provincial support collaborative innovation, play a good role model in the support area of advanced innovation and development, the establishment of collaborative innovation for regional economic development, in order to contribute to the industrialization of college enterprise project outcomes, a significant economic and social benefits to achieve the ultimate goal of innovation and entrepreneurship education.

\section{Acknowledgements}

Project 1:2015 Jilin Province Educational Science "12th Five-Year" general planning topic < Ordinary Higher Agricultural College Students Innovation Talent Training Mode Research > research results (No.: GH150216)

Project 2: One of the results of "agricultural university students study entrepreneurship education system", Jilin Provincial Department of education "12th Five-Year" social science research project (ID: ilin Education Science topics [2015] NO.118)

\section{References}

[1] Hu Jintao. At Tsinghua University to celebrate the 100th anniversary of the founding of the General Assembly on the speech [N]. People's Daily, 2011-04-25 (1)

[2] Xue Chuanhui. Discuss on higher school collaborative innovation strategy [J] Contemporary Education Sciences, 2012 (7): 29

[3] Lu Haibo, Li Guo-Jie, Xiao Ke, etc. [J]. Liaoning agricultural colleges and universities to improve the ability of agricultural science and technology innovation path mode. Higher agricultural education, 2012, (6). 
[4] Han Qiang. Agriculture strong and efficient collaborative innovation: models, problems and countermeasures $[\mathrm{J}]$ higher agricultural education, 2013-5,5: 15-19

[5] Dai Jing. Science Fusion entrepreneurial ability of agricultural university students Perspective culture studies [D], 2014.6

[6] Wang Shuguo. Strengthen collaborative innovation to build a first-class university [J] University (Academic Edition), 2011 (8): 4-9

[7] Li Zhongyun, Deng Xiuxin .Collaborative innovation of academic difficulties, path and policy recommendations [J] Chinese higher education, 2011 (17): 11-13

[8] Lu Haiyan. Thinking on the construction of practical teaching system from the perspective of innovative talents cultivation [J]. China Electric Power Education Education, 2013 (10).

[9] Shang Hengzhi. College students' entrepreneurship education curriculum system of [J]. education research and experiment, 2009:7.

[10]Feng Xiao. The practice and exploration of innovation and entrepreneurship education in agricultural colleges and universities [J]. China's agricultural education, 2015, 05:1-7. 